\title{
Is sperm FISH analysis still useful for Robertsonian translocations? Meiotic analysis for 23 patients and review of the literature
}

Anna Lamotte ${ }^{1,3 \dagger}$, Guillaume Martinez ${ }^{2,3,4 \dagger}$, Françoise Devillard² , Jean-Pascal Hograindleur ${ }^{3,4}$, Véronique Satre ${ }^{2,3,4}$, Charles Coutton 2,3,4, Radu Harbuz ${ }^{2}$, Florence Amblard ${ }^{2}$, James Lespinasse ${ }^{5}$, Mehdi Benchaib ${ }^{6}$, Julien Bessonnat ${ }^{1}$, Sophie Brouillet ${ }^{1,3}$ and Sylviane Hennebicq ${ }^{1,3,4^{*}}$

\begin{abstract}
Background: Robertsonian translocations (RobT) are common structural chromosome rearrangements where carriers display a majority of chromosomally balanced spermatozoa from alternate segregation mode. According to some monotony observed in the rates of balanced segregation, is sperm FISH analysis obsolete for RobT carriers?

Methods: Retrospective cohort research study on 23 patients analyzed in our center from 2003 to 2017 and compared to the data of 187 patients in literature from 1983 to 2017.

Robertsonian translocation carriers were divided in six groups according to the chromosomes involved in the translocation: 9 patients from our center and 107 from literature carrying 45,XY,der(13;14) karyotype, 3 and 35 patients respectively with 45,XY,der(14;21), 5 and 11 patients respectively with $45, X Y$, der(13;15), 4 and 7 patients respectively with 45,XY,der(14;15), 1 and 4 patients respectively with 45,XY,der(13;22),and 1 and 10 patients respectively with $45, X Y$, der(14;22).
\end{abstract}

Results: Alternate segregation mode is predominant in our group of Robertsonian translocation carriers with $73.45 \%$ \pm 8.05 of balanced spermatozoa ( $\min 50.92 \%$; max 89.99\%). These results are compliant with the data from literature for all translocations types $(p>0.05)$ and are consistent among the different types of Robertsonian translocations $(p>0.05)$ except for der(13;15) that exhibit lower balanced spermatozoa rates ( $p<0.05$ versus der(13;14), der(14;21), (13;21) and der(15;22)). Normozoospermic patients also display a significantly $(p<0.01)$ higher rate of balanced sperm cells than patients with abnormal seminograms whatever the defect implied.

Conclusions: According to the discrepancies observed between der(13;15) and all the other Rob T carriers, the differences observed among patients presenting normal and abnormal sperm parameters and the input in genetical counselling, sperm FISH does not seem obsolete for these patients. Moreover, it seems important to collect more data for rare RobT.

Keywords: Robertsonian translocation, Sperm FISH, Meiotic segregation, Spermatozoa, Preimplantation genetic diagnosis

\footnotetext{
* Correspondence: shennebicq@chu-grenoble.fr

tEqual contributors

${ }^{1} \mathrm{CHU}$ de Grenoble, UF de Biologie de la procréation, F-38000 Grenoble,

France

${ }^{3}$ Université Grenoble Alpes, F-38000 Grenoble, France

Full list of author information is available at the end of the article
} 


\section{Résumé}

Contexte: Le mode de ségrégation chromosomique le plus fréquemment observé chez les patients porteurs de translocation robertsonienne est. un mode équilibré. Les données semblent varier peu selon la translocation analysée. La relative constance des résultats dans le cas de ces translocations robertsoniennes rend elle inutile ces analyses chromosomiques pour ces patients?

Patients et méthodes: Nous avons analysé de façon rétrospective les données spermatiques et de ségrégation méiotique de 23 patients porteurs de translocation robertsonienne, de 2003 à 2017 et comparé les résultats observés à ceux décrits dans la littérature pour 187 patients.

Résultats: Le mode de ségrégation alterne est. prépondérant dans notre série de patients avec $73.45 \% \pm 8.05$ de spermatozoïdes équilibrés (min 50.92\%; max 89.99\%). Ces résultats sont en accord avec les données de la littérature, toutes translocations confondues et selon le type de translocation $(p>0.05)$ sauf pour la translocation der(13;15) où ces taux sont significativement plus faibles ( $p<0.05$ vs der(13;14), der(14;21), (13;21) et der(15;22)). Nous observons également des taux de spermatozoïdes équilibrés significativement plus élevés chez les patients à spermogramme normal $(p<0.01)$.

Conclusions: Les différences observées dans les taux d'aneuploïdies entre les translocations der(13;15) et les autres translocations robertsoniennes et entre les porteurs de translocation à spermogramme normal ou altéré, et l'utilité de ces données dans le conseil génétique conduisent à poursuivre l'analyse systématique de la ségrégation méiotique pour les patients porteurs de translocations robertsoniennes et ceci particulièrement pour les translocations rares.

Mots-clés: Translocation robertsonienne, hybridation in situ, ségrégation méiotique, spermatozoïde, diagnostic génétique préimplantatoire

\section{Background}

Robertsonian translocation (RobT) is a frequent structural chromosomal aberration with an incidence of 1.23 per thousand births [1]. Carriers present a karyotype with 45 chromosomes resulting from centromeric fusion of two acrocentric chromosomes $(13 ; 14 ; 15 ; 21$ or 22$)$. Most common Robertsonian translocations are der (13; 14) and $\operatorname{der}(14 ; 21)$ with a frequency of $73 \%$ and $10 \%$ respectively [2]. Unbalanced segregation of these chromosomes through meiosis can result in recurrent pregnancy loss if the unbalanced chromosomal content is not viable, or birth of a child with severe malformations and mental retardation in case of viability. The prevalence of RobT carriers in recurrent pregnancy loss and infertile male population are at least ten times higher (respectively $1.1 \%$ and $3 \%$ versus $0,1 \%$ ) than in general population [2-5]. Knowing the rates of balanced and unbalanced segregation including the different types of unbalanced modes is thus of great importance in genetic counselling for these couples. Moreover, male carriers can present oligoasthenoteratozoospermia leading to procreation issues.

During meiosis, pairing and segregation is possible through formation of a trivalent during prophase I (Fig. 1). Alternate segregation results in two balanced gametes containing either normal chromosomes A and $\mathrm{B}$ or the derivate $\operatorname{der}(\mathrm{A} ; \mathrm{B})$. FISH analysis does not allow differentiating these, neither in sperm, nor in the embryos. The karyotype of the conceptus is then either normal or presents the same translocation as the parent, possibly leading to abnormality in the child's offspring at adulthood. The adjacent segregation modes lead either to sperm nullosomy or sperm disomy. In case of nullosomy, the conceptus presents a monosomy which is not viable, while in case of a sperm disomy, the conceptus presents a trisomy, which can be viable (from several hours to several years or more in trisomy 21). The 3:0 mode of segregation leads to sperm double nullosomy or disomy, leading to unviable monosomic or trisomic conceptus. Detailed analysis of the sperm chromosomal content can thus help genetical counselling through a quantification of (i) the chances of a viable pregnancy (balanced content of sperm and conceptus) and the risk of (ii) recurrent pregnancy loss (unviable monosomy or trisomy) or (iii) possibly viable trisomy. The risk of unbalanced conceptus highlights the importance of chromosomal meiotic segregation analysis. Preimplantation genetic diagnosis (PGD) for RobT carriers reduces the risk of pregnancy loss or multiple congenital anomalies and intellectual disability (MCA-ID) through selection and transfer of normal/balanced embryos.

The first analyses of meiotic segregation variants were done by heterospecific oocyte fertilization followed by sperm karyotyping. This technique was long and fastidious. It only allowed the analysis of a few number of 


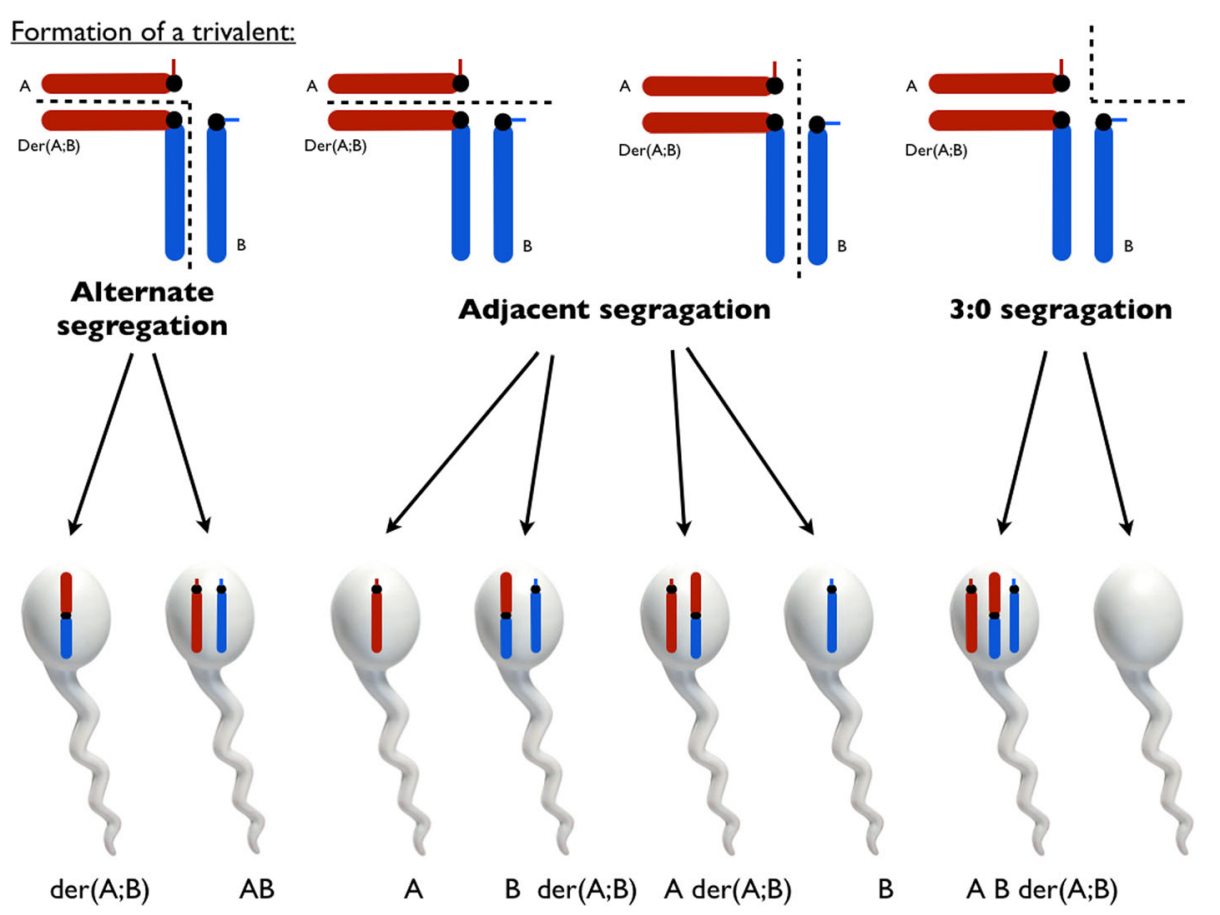

Fig. 1 Formation of trivalent and its segregation in meiosis

sperm, moreover restricted to the fertile ones. One advantage of this technique was to distinguish between normal and balanced sperm. Development of fluorescence in-situ hybridization (FISH) technique has simplified the analysis of sperm chromosomal content and has enabled to collect numerous data on meiotic segregation and balanced and unbalanced rearrangements. This technique combined to automated slides scanning allows the analysis of a large number of sperm cells and is for several years used in routine practice.

The primary objective of this study was to assess the variability of meiotic segregation in sperm of RobT carriers. We thus, analyzed 23 new carriers and literature data of 187 patients. We also looked for factors influencing meiotic segregation rates.

\section{Methods}

\section{Patients}

Twenty three male patients aged 26 to 40 years, carrying a RobT, were included in this retrospective cohort study. They consulted for fertility issues in the genetic and procreation department of university hospital of Grenoble between january 2003 and april 2017, except for three of them who were referred by three other french centers (service de génétique, CHU de Reims; service de génétique, $\mathrm{CH}$ de Chambéry; centre d'AMP, HFME, CHU de Lyon, France).

Karyotype performed on blood cells was 45,XY,der(13; 14)(q10;q10) in 9 patients, 45,XY,der(13;15)(q10;q10) in
5 patients, 45,XY,der(14;15)(q10;q10) in 4 patients, 45,XY,der(14;21)(q10;q10) in 3 patients, 45,XY,der(13;22) (q10;q10) in one patient and 45,XY,der(14;22)(q10;q10) in one patient.

Sperm FISH analyses performed between 2004 and 2006, as a research project, were submitted to a signed inform consent of all the patients with approval of the study by the ethic committee of the University Hospital of Grenoble. Since 2006, the analysis was achieved as a routine test, ruled by a signed informed genetic consent for all patients. The sperm preparation and sperm FISH techniques remained identical over the entire period of study.

\section{Sperm preparation}

Semen samples were collected in a sterile container after masturbation. Liquefaction was obtained after $30 \mathrm{~min}$ at $37{ }^{\circ} \mathrm{C}$. Sperm concentration, motility and morphology were determined according to WHO criteria (World Health Organization, 1999 for the analyses done until 2009 and WHO, 2010 for the analyses performed later on) [6].

\section{Sperm FISH technique}

Samples were washed twice with $5 \mathrm{ml}$ of phosphatebuffered saline (PBS) $1 \mathrm{X}$ and fixed in a methanol/acetic acid $(3: 1, v / v)$ solution. Cells were spread on Superfrost $\odot$ (Kindler, Freidburg Germany) slides and air dried at room temperature. Sperm head decondensation was 
performed in $\mathrm{NaOH} 1 \mathrm{M}$ solution, followed by two washes in 2X standard saline citrate (SSC) and dehydration in a $70,90 \%$ and pure ethanol solution. Samples were then hybridized overnight with probes of interest for dual-color FISH, depending on the chromosomes involved (Table 1). The scoring of the fluorescent signals was performed by two independent investigators, using an epifluorescence microscope (Nikon Eclipse 80i or Leica DM 5000B) with adapted filter DAPI, FITC, Orange or triple-band. Manual spot count was performed following strict criteria [7]. Automated FISH results were obtained with Metafer Slide Scanning System and MetaCyte software (Metasystems ${ }^{\circ}$, Germany), as reported previously [8], with over one thousand cells analyzed when preparation allowed it.

\section{Literature analysis}

Literature analysis was mainly performed on PUBMED. Searching was performed using the following MESH terms: Robertsonian translocation/sperm FISH/meiotic segregation. A total of 171 publications were found. Among them, 44 publications [9-52] about meiotic segregation of sperm from Robertsonian translocation carriers were found between 1983 and 2017 (Table 2).

\section{Data analyzed}

Variables analyzed were: sperm concentration $\left(10^{6} / \mathrm{ml}\right)$, motility (\%), morphology (\%) and meiotic segregation rates of different variants (\%).

\section{Statistical analysis}

Data were treated with $\mathrm{R}$ software (version number 2 . 14.1). A probability value of less than 0.05 was considered to be statistically significant.

\section{Results}

\section{Semen parameters}

As summarized in Tables 3, 4 patients were normozoospermic, 6 were oligoasthenozoospermic, 6 were oligoasthenoteratozoospermic (OAT), 3 were oligoteratozoospermic, 2 were asthenozoospermic, and 2 were oligozoospermic.

\section{Sperm FISH analysis}

The number of analyzed sperm ranged from 91 to 1950 for each patient, with a total of 18,261 spermatozoa. Segregation results are illustrated in Fig. 2 and detailed in Table 4 with insight in each mode: alternate, adjacent and 3:0. Our results confirmed a majority of balanced spermatozoa for all patients with a mean \pm SE of $73.45 \pm$ $8.05 \%$ for all RobT ( $\min 50.92$; $\max 89.99$ ). The rate of unbalanced spermatozoa resulting from adjacent mode of segregation represented $25.25 \pm 7.63 \%$ ( $\min 10.01 \%$; $\max 49.08 \%)$. The 3:0 segregation mode represented 1 . $29 \pm 1.50 \%$ ( $\min 0 \%$; $\max 8.06 \%$ ). Mean disomy rates vary from $2.94 \%$ to $6.51 \%(\min =0.21 \%, \max =13.85 \%)$ when comparing all the translocations, while mean nullosomy rates vary from $2.34 \%$ to $12.36 \%$ ( $\min =0.00 \%$; $\max =16.97 \%$ ). For each chromosome, mean disomy rate is always lower than mean nullosomy rate.

\section{Analysis of the segregation data available in the literature} Bibliographic references about sperm FISH analysis of Robertsonian translocation carriers are presented in Table 2. Forty four articles have been published from 1983 to 2017 dealing with meiotic segregation in sperm with thirty nine for the same RobT as in our study. It overall summarized the FISH analysis of 210 patients.

Our segregation rates were compliant with the data from literature for all translocation types (our study versus literature): $\operatorname{der}(13 ; 14) 73.43 \pm 7 \%$ versus $83.29 \pm 8$. $72 \%$, der(13;15) $69.91 \pm 12.62 \%$ versus $79.73 \pm 6.73 \%$, $\operatorname{der}(14 ; 15) 76.80 \pm 7.96 \%$ versus $84.51 \pm 5.58 \%$, $\operatorname{der}(14 ; 21)$ $74.35 \pm 18.9 \%$ versus $83.45 \pm 8.3 \%(p>0.05$, t-test). Statistics were not available for $\operatorname{der}(13 ; 22)$ and $(14 ; 22)$ as we only added one patient.

Altogether, balanced segregation rates were consistent among the different types of RobT ( $p>0.05$, t-test)

Table 1 Probes used in FISH analysis

\begin{tabular}{|c|c|c|}
\hline Patient & Translocation & Probes \\
\hline P1 to $P 9$ & $\operatorname{der}(13 ; 14)(q 10 ; q 10)$ & LSI $13 q 14$ SG (Vysis ${ }^{\oplus}$, ABBOTT) \& TelVysion 14q SO (Vysis \\
\hline P10 to P14 & $\operatorname{der}(13 ; 15)(q 10 ; q 10)$ & LSI ${ }^{\circledast}$ 13q14 SG (Vysis ${ }^{\oplus}$, ABBOTT) \& TelVysion 15q SO (Vysis ${ }^{\oplus}$, ABBOTT) \\
\hline${ }^{\mathrm{a} P 10}$ and P11 & $\operatorname{der}(13 ; 15)(q 10 ; q 10)$ & $13 q 32.1$ orange (BlueGnome) \& CEP 15 SA (Vysis $\left.{ }^{\oplus}, \mathrm{ABBOTT}\right)$ \\
\hline P15 & $\operatorname{der}(13 ; 22)(q 10 ; q 10)$ & $13 q 32.1$ orange (BlueGnome) \& LSI 22 (BCR) SG (Vysis ${ }^{\oplus}$, ABBOTT) \\
\hline P16 and P17 & $\operatorname{der}(14 ; 15)(q 10 ; q 10)$ & TelVysion 14q SO (Vysis ${ }^{\oplus}$, ABBOTT) \& CEP 15 SA (Vysis ${ }^{\oplus}$, ABBOTT) \\
\hline ap16 & $\operatorname{der}(14 ; 15)(q 10 ; q 10)$ & Subtelomere 14q green (Cytocell Aquarius) \& CEP 15 SA (Vysis ${ }^{\oplus}$, ABBOTT) \\
\hline P18 and P19 & $\operatorname{der}(14 ; 15)(q 10 ; q 10)$ & TelVysion 14q SO (Vysis ${ }^{\oplus}$, ABBOTT) \& CEP 15 SA (Vysis ${ }^{\oplus}$, ABBOTT) \\
\hline P20 to P22 & $\operatorname{der}(14 ; 21)(q 10 ; q 10)$ & TelVysion 14q SO (Vysis $\left.{ }^{\oplus}, \mathrm{ABBOTT}\right)$ \& Subtelomere 21q green (Cytocell Aquarius) \\
\hline P23 & $\operatorname{der}(14 ; 22)(q 10 ; q 10)$ & Subtelomere 14q green (Cytocell Aquarius) \& Tel22q SO (Amplitech) \\
\hline
\end{tabular}

${ }^{a}$ patients for whom a second analysis was performed because of insufficient initial count 
Table 2 Robertsonian translocation carriers with meiotic segregation analysis in literature

\begin{tabular}{|c|c|c|c|c|c|c|c|c|c|c|}
\hline & $13 ; 14$ & $14 ; 21$ & $13 ; 15$ & $14 ; 15$ & $14 ; 22$ & $13 ; 21$ & $13 ; 22$ & $21 ; 22$ & $15 ; 22$ & $15 ; 21$ \\
\hline Wang et al. 2017 & 6 & 3 & & 1 & & & 1 & 1 & & \\
\hline Song et al. 2016 & & & & 1 & & & & & & \\
\hline Godo et al. 2015 & 10 & & & & & & 1 & & & \\
\hline Sobotka et al. 2015 & & & & & 1 & & & & & \\
\hline Xu et al. 2014 & & & & 1 & & & & & & \\
\hline Perrin et al. 2013 & 1 & 1 & 1 & & & & & & & \\
\hline Pylyp et al. 2013 & 5 & 3 & & & & 1 & & & & \\
\hline Rouen et al. 2013 & 1 & 1 & & & & & & & & \\
\hline Rouen et al. 2013 & 7 & 1 & 1 & & & & & & & \\
\hline Vozdova et al. 2013 & 11 & 1 & & & & & & & 1 & \\
\hline Bernicot et al 2012 & & & & & & 1 & & & 1 & \\
\hline Cassuto et al. 2011 & 1 & 1 & & & & & & & & \\
\hline Ferfouri et al. 2011 & 16 & 8 & 1 & & 3 & & & & & 1 \\
\hline Mahjoub et al. 2011 & 5 & & & & & & & & & \\
\hline Anton et al. 2010 & & 3 & & & & & 1 & & & \\
\hline Brugnon et al. 2010 & 1 & 1 & 1 & & 2 & & & & & \\
\hline Perrin et al. 2010 & 3 & & & & & & & & & \\
\hline Perrin et al. 2009 & 3 & 1 & & & & & & & & \\
\hline Nishikawa et al. 2008 & 1 & 2 & & & & 1 & & & & \\
\hline Chen et al. 2007 & 4 & & & & 1 & 1 & & & & \\
\hline Kekesi et al 2007 & 1 & & & & & & & & & \\
\hline Brugnon et al. 2006 & 3 & & 1 & & & & & & & \\
\hline Hatakeyama et al 2006 & & & & & & 1 & & & & \\
\hline Moradkhani et al 2006 & & & 2 & 2 & & & & & & \\
\hline Moradkhani et al 2006 & & & & & 3 & & & & & \\
\hline Ogur et al 2006 & 7 & 2 & 2 & 2 & & & & 1 & & \\
\hline Tang et al 2006 & & 1 & & & & & & & & \\
\hline Anahory 2005 & & & & & & & 1 & & & \\
\hline Rives et al 2005 & & & 1 & & & & & & & \\
\hline Roux et al 2005 & 3 & & & & & & & & & \\
\hline Anton et al 2004 & 7 & & & & & & & & & \\
\hline Frydman et al 2001 & 3 & 3 & & & & & & & & \\
\hline Morel et al 2001 & 3 & & & & & & & & & \\
\hline Escudero et al 2000 & 2 & & & & & & & & & \\
\hline Honda et al 2000 & & 1 & & & & & & & & \\
\hline${ }^{a}$ Ogawa et al. 2000 & 1 & & & & & & & & & \\
\hline Mennicke et al. 1997 & & & & & & & & 1 & & \\
\hline Rousseaux et al 1995 & & 1 & & & & & & & & \\
\hline${ }^{a}$ Martin et al 1992 & & & & & & & & & 1 & \\
\hline${ }^{a}$ Syme et al 1992 & & & & & & & & 1 & & \\
\hline${ }^{a}$ Pellestor et al. 1990 & & & 1 & & & & & & & \\
\hline${ }^{a}$ Martin et al. 1988 & 1 & & & & & & & & & \\
\hline${ }^{a}$ Pellestor et al. 1987 & 1 & & & & & & & & & \\
\hline${ }^{a}$ Balkan et al. 1983 & & 1 & & & & & & & & \\
\hline
\end{tabular}


Table 2 Robertsonian translocation carriers with meiotic segregation analysis in literature (Continued)

\begin{tabular}{llrrrrrrrrrr}
\hline & $13 ; 14$ & $14 ; 21$ & $13 ; 15$ & $14 ; 15$ & $14 ; 22$ & $13 ; 21$ & $13 ; 22$ & $21 ; 22$ & $15 ; 22$ & $15 ; 21$ \\
\hline Literature & 107 & 35 & 11 & 7 & 10 & 5 & 4 & 4 & 3 & 1 \\
Our study & 9 & 3 & 5 & 4 & 1 & 0 & 1 & 0 & 0 & 0 \\
Total & 116 & 38 & 16 & 11 & 11 & 5 & 5 & 4 & 3 \\
\% total & 55,24 & 18,10 & 7,62 & 5,24 & 5,24 & 2,38 & 2,38 & 1,90 & 1,43 & 0,48 \\
\hline
\end{tabular}

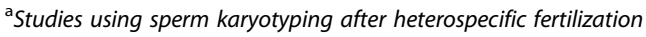

except for der(13;15) that exhibited lower balanced spermatozoa rates (Fig. 3). Der(13;15) segregation rates were statistically different $(p<0.05, \mathrm{t}$-test) from those from the two most common Robertsonian translocation $\operatorname{der}(13 ; 14)$ and $\operatorname{der}(14 ; 21)$, and two less common der(13; $21)$ and $\operatorname{der}(15 ; 22)$.

\section{Correlation between segregation data and semen analysis}

From the 187 selected carriers of literature, sperm analysis data were available for 159 , and added to our 23 patients. Among all, 33 were normozoospermic (18.13\%) and 149 exhibited abnormal seminogram (81.87\%). Oligozoospermia was found in 133 patients (73.08\%), asthenozoospermia in 109 (59.89\%) and teratozoospermia in 119 (65.38\%). Twenty three patients had a single anomaly (12.64\%), 46 two anomalies (25.27) and 83 displayed OAT (45.60\%).

As shown in Fig. 4, normozoospermic patients display a significantly $(p<0.01$, t-test) higher rate of balanced sperm cells (85\%) than patients with seminogram anomalies $(81.3 \%)$, whatever the number or the type of anomalies involved $(p>0.05$, t-test).

\section{Discussion}

Thanks to the twenty-three new patients of this study, literature reaches more than two hundred

Table 3 Robertsonian translocation carriers age, karyotype and semen parameters

\begin{tabular}{|c|c|c|c|c|c|c|}
\hline \multirow[t]{2}{*}{ Patient } & \multirow[t]{2}{*}{ Age } & \multirow[t]{2}{*}{ Karyotype } & \multicolumn{3}{|l|}{ Semen parameters } & \multirow[t]{2}{*}{ Seminogram } \\
\hline & & & Concentration $\left(\times 10^{\wedge} 6 / \mathrm{ml}\right)$ & Motility (\%) & (\%) Normal morphology & \\
\hline$\overline{P 1}$ & 36 & $45, X Y, \operatorname{der}(13 ; 14)(q 10 ; q 10)$ & 4,5 & 20 & 4 & Oligoasthenozoospermia \\
\hline P2 & 26 & $45, X Y, \operatorname{der}(13 ; 14)(q 10 ; q 10)$ & 0,6 & 36 & 3 & Oligoasthenoteratozoospermia \\
\hline P3 & 34 & 45,XY,der(13;14)(q10;q10) & 0,48 & 17 & 3 & Oligoasthenoteratozoospermia \\
\hline P4 & 38 & 45,XY,der(13;14)(q10;q10) & 28 & 40 & 9 & Normozoospermia \\
\hline P5 & 29 & $45, X Y, \operatorname{der}(13 ; 14)(q 10 ; q 10)$ & 22,3 & 50 & 16 & Normozoospermia \\
\hline P6 & 33 & $45, X Y, \operatorname{der}(13 ; 14)(q 10 ; q 10)$ & 2,2 & 20 & 2 & Oligoasthenoteratozoospermia \\
\hline P7 & 38 & $45, X Y, \operatorname{der}(13 ; 14)(q 10 ; q 10)$ & 25 & 5 & 2 & Oligoasthenoteratozoospermia \\
\hline P8 & 36 & $45, X Y, \operatorname{der}(13 ; 14)(q 10 ; q 10)$ & 2 & 30 & 4 & Oligoasthenozoospermia \\
\hline P9 & 32 & $45, X Y, \operatorname{der}(13 ; 14)(q 10 ; q 10)$ & 0.007 & 17 & 0 & Oligoasthenoteratozoospermia \\
\hline P10 & 32 & $45, X Y, \operatorname{der}(13 ; 15)(q 10 ; q 10)$ & 13 & 34 & 8 & Oligoasthenozoospermia \\
\hline P11 & 27 & $45, X Y, \operatorname{der}(13 ; 15)(q 10 ; q 10)$ & 23 & 60 & 4 & Normozoospermia \\
\hline P12 & 28 & $45, X Y, \operatorname{der}(13 ; 15)(q 10 ; q 10)$ & 0,9 & 48 & 13 & Oligozoospermia \\
\hline P13 & 35 & 45,XY,der(13;15)(q10;q10) & 0,02 & 13 & 2 & Oligoasthenoteratozoospermia \\
\hline P14 & 27 & $45, X Y, \operatorname{der}(13 ; 15)(q 10 ; q 10)$ & 5 & 45 & 0 & Oligoteratozoospermia \\
\hline P15 & 35 & $45, X Y, \operatorname{der}(13 ; 22)(q 10 ; q 10)$ & 7,3 & 45 & 3 & Oligoteratozoospermia \\
\hline P16 & 38 & $45, X Y, \operatorname{der}(14 ; 15)(q 10 ; q 10)$ & 27 & 30 & 39 & Asthenozoospermia \\
\hline P17 & 33 & 45,XY,der(14;15)(q10;q10) & 35 & 30 & 21 & Asthenozoospermia \\
\hline P18 & 31 & $45, X Y, \operatorname{der}(14 ; 15)(q 10 ; q 10)$ & 2,2 & 30 & 59 & Oligoasthenozoospermia \\
\hline P19 & 30 & 45,XY,der(14;15)(q10;q10) & 5 & 35 & 15 & Oligoasthenozoospermia \\
\hline P20 & 40 & $45, X Y, \operatorname{der}(14 ; 21)(q 10 ; q 10)$ & 42 & 45 & 17 & Normozoospermia \\
\hline P21 & 36 & $45, X Y, \operatorname{der}(14 ; 21)(q 10 ; q 10)$ & 2,7 & 40 & 11 & Oligozoospermia \\
\hline P22 & 27 & $45, X Y, \operatorname{der}(14 ; 21)(q 10 ; q 10)$ & 0,4 & 16 & 5 & Oligoasthenozoospermia \\
\hline P23 & 39 & $45, X Y, \operatorname{der}(14 ; 22)(q 10 ; q 10)$ & 8 & 45 & 2 & Oligoteratozoospermia \\
\hline
\end{tabular}


Table 4 Meiotic segregation of Robertsonian translocation carriers

\begin{tabular}{|c|c|c|c|c|c|c|c|}
\hline Patient & $\%$ Alt & $\%$ Adjacent & & & & $\%$ 3:0 & $\%$ unbalanced \\
\hline \multicolumn{8}{|l|}{$\operatorname{der}(13 ; 14)$} \\
\hline & balanced & disomy 13 & nullisomy 13 & disomy 14 & nullisomy 14 & $3: 0$ & unbalanced \\
\hline P1 & 72.76 & 6.34 & 8.21 & 2.99 & 6.72 & 2.99 & 27.24 \\
\hline P2 & 71.69 & 4.57 & 6.39 & 7.31 & 10.05 & 0.00 & 28.31 \\
\hline P3 & 64.94 & 4.60 & 15.52 & 8.62 & 5.75 & 0.57 & 35.06 \\
\hline P4 & 84.86 & 2.83 & 4.66 & 3.16 & 4.49 & 0.00 & 15.14 \\
\hline P5 & 85.95 & 2.42 & 5.82 & 2.75 & 3.07 & 0.00 & 14.05 \\
\hline P6 & 75.39 & 6.84 & 6.29 & 5.74 & 5.52 & 0.22 & 24.61 \\
\hline P7 & 78.52 & 7.21 & 6.38 & 3.52 & 4.36 & 0.00 & 21.48 \\
\hline P8 & 66.08 & 4.59 & 3.81 & 9.97 & 12.12 & 3.42 & 33.92 \\
\hline P9 & 60.69 & 13.08 & 3.15 & 7.75 & 7.27 & 8.06 & 39.31 \\
\hline Mean & 73.43 & 5.83 & 6.69 & 5.76 & 6.59 & 1.70 & 26.57 \\
\hline \multicolumn{8}{|l|}{$\operatorname{der}(13 ; 15)$} \\
\hline & balanced & disomy 13 & nullisomy 13 & disomy 15 & nullisomy 15 & $3: 0$ & unbalanced \\
\hline P10 & 66.80 & 6.40 & 7.60 & 8.80 & 10.40 & 0.00 & 33.20 \\
\hline P11 & 68.94 & 4.61 & 7.01 & 4.81 & 14.63 & 0.00 & 31.06 \\
\hline P12 & 81.32 & 1.10 & 6.59 & 3.30 & 6.59 & 1.10 & 18.68 \\
\hline P13 & 50.92 & 9.17 & 12.84 & 10.09 & 16.97 & 0.00 & 49.08 \\
\hline P14 & 81.57 & 3.66 & 2.66 & 3.97 & 3.76 & 4.39 & 18.43 \\
\hline Mean $\pm S D$ & 69.91 & 4.99 & 7.34 & 6.19 & 10.47 & 1.10 & 30.09 \\
\hline \multicolumn{8}{|l|}{$\operatorname{der}(13 ; 22)$} \\
\hline & balanced & disomy 13 & nullisomy 13 & disomy 22 & nullisomy 22 & $3: 0$ & unbalanced \\
\hline P15 & 72.78 & 4.63 & 9.51 & 4.39 & 8.05 & 0.73 & 27.32 \\
\hline \multicolumn{8}{|l|}{$\operatorname{der}(14 ; 15)$} \\
\hline & balanced & disomy 14 & nullisomy 14 & disomy 15 & nullisomy 15 & $3: 0$ & unbalanced \\
\hline P16 & 71.80 & 7.00 & 10.60 & 3.60 & 7.00 & 0.00 & 28.20 \\
\hline P17 & 83.90 & 0.85 & 4.24 & 0.21 & 10.81 & 0.00 & 16.10 \\
\hline P18 & 83.26 & 2.48 & 4.75 & 1.24 & 8.26 & 0.00 & 16.74 \\
\hline P19 & 68.26 & 5.49 & 4.51 & 7.33 & 12.56 & 1.85 & 31.74 \\
\hline Mean $\pm S D$ & 76.80 & 3.95 & 6.03 & 3.10 & 9.66 & 0.46 & 23.20 \\
\hline \multicolumn{8}{|l|}{$\operatorname{der}(14 ; 21)$} \\
\hline & balanced & disomy 14 & nullisomy 14 & disomy 21 & nullisomy 21 & $3: 0$ & unbalanced \\
\hline P20 & 89.99 & 3.24 & 0.99 & 1.97 & 3.81 & 0.00 & 10.01 \\
\hline P21 & 53.34 & 11.35 & 28.46 & 3.11 & 0.00 & 3.73 & 46.66 \\
\hline P22 & 79.71 & 4.92 & 7.63 & 3.73 & 3.22 & 0.79 & 20.29 \\
\hline Mean $\pm S D$ & 74.35 & 6.51 & 12.36 & 2.94 & 2.34 & 1.51 & 25.65 \\
\hline \multicolumn{8}{|l|}{$\operatorname{der}(14 ; 22)$} \\
\hline & balanced & disomy 14 & nullisomy 14 & disomy 22 & nullisomy 22 & $3: 0$ & unbalanced \\
\hline P23 & 76.09 & 5.07 & 5.92 & 4.21 & 6.78 & 1.93 & 23.91 \\
\hline
\end{tabular}

descriptions of meiotic segregation of RobT carriers. Compiling of these data is especially important for rare RobT, like $\operatorname{der}(13 ; 15)$ for which we add 5 carriers to the 11 already known $(+45 \%), \operatorname{der}(14 ; 15)$ with 4 new patients to the 7 previously published (+57\%) and $\operatorname{der}(13 ; 22)$ with one addition to the 4 patients already presented $(+25 \%)$.

Our rates of balanced segregation (73.45 $\pm 8.05 \%)$ are compliant with the previous studies $(p>0.05)$ for each translocation versus data from publications listed 


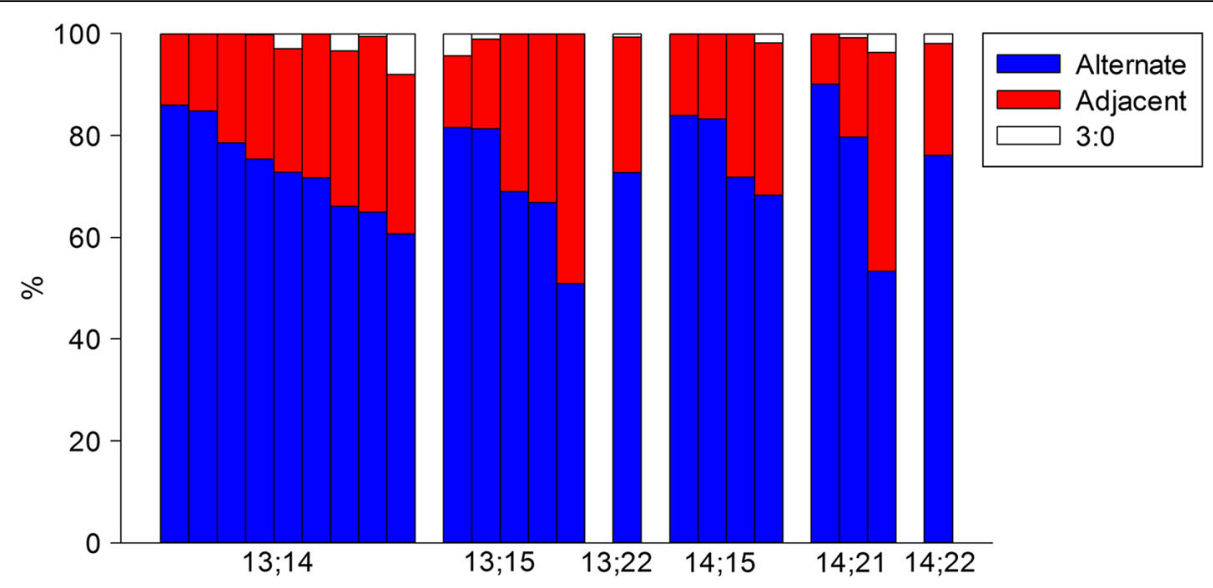

Fig. 2 Rates of different variants in meiotic segregation

in Table 4, showing the predominance of alternate segregation for all carriers. Similar to literature (41. $7 \%)$, most of our patients (39.1\%) exhibit balanced segregation rates between 75 and $85 \%$. Patients with rates under $65 \%$ or over $90 \%$ only represent a small proportion of global population both in our study $(17.4 \%)$ and in literature (16.6\%).

It is commonly assumed that rearranged chromosomes of RobT carriers have similar meiotic behavior, regardless of the chromosomes involved ([34], data from 41 carriers). This hypothesis is strongly supported by the similarity of balanced gamete rates among the different RobT carriers. We demonstrate that all RobT segregation rates are similar to each other $(p>0.05)$, except for $\operatorname{der}(13 ; 15)$ whose rates are significantly lower $(p<0.05)$ than $\operatorname{der}(13 ; 14)$ and $\operatorname{der}(14 ; 21)$, the two most frequent translocations, and $\operatorname{der}(13 ; 21)$ and $\operatorname{der}(15 ; 22)$. The limited size of the cohorts of the other translocations probably explains the lack of significance in segregation rates $(p=0.13$ vs $\operatorname{der}(14 ; 15) n=11 ; p=0.17$ vs $\operatorname{der}(14 ; 22) n=11 ; p=0.46$ vs $\operatorname{der}(13 ; 22) n=5)$. No clue has been found so far to explain the difference between der(13;15) segregation rate and the

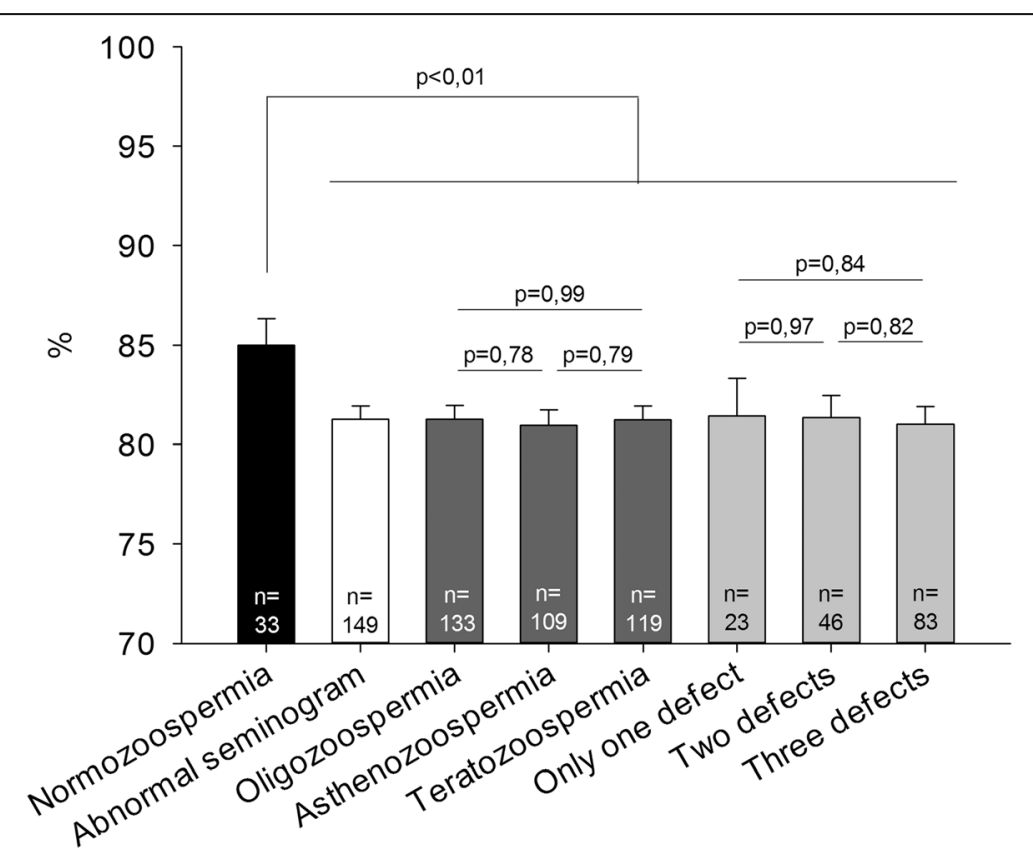

Fig. 3 Comparative analysis of the rates of balanced spermatozoa between each RobT. Legend: $n=$ number of patients, ${ }^{*} p$-value $<0.05$ versus der(13;15). Statistical analysis not possible for der(15;21) due to the number of patients 


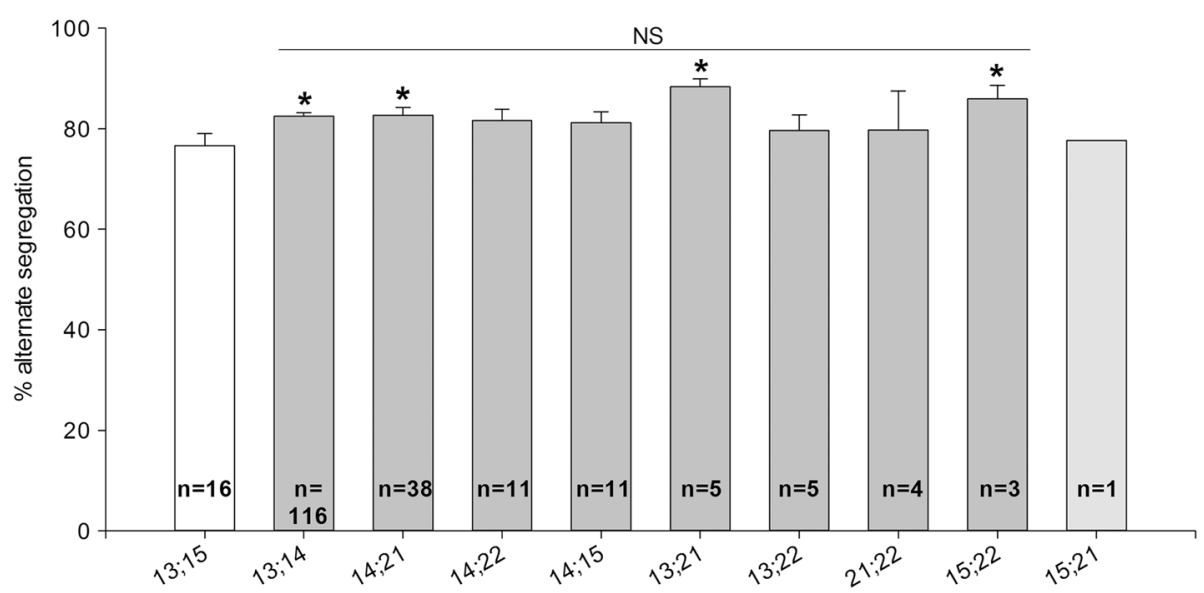

Fig. 4 Balanced spermatozoa rates among normozoospermic patients and patients with abnormal seminogram. Legend: $n=$ number of patients

other RobT. It could be due either to the structure of the chromosomes involved in the translocation, or to the spermatogenesis itself. We also clearly show that mean disomy rates are lower than mean nullosomy rates, whatever the chromosome analyzed and that the discrepancies observed among the rates for patients carrying the same translocation are important. When giving genetical counselling to the patients and thinking about preimplantation diagnosis, oocyte fertilization by a nullosomic sperm leads to miscarriage, while oocyte fertilization by a disomic sperm can lead to the birth of a child with MCA-ID. The choice of preimplantation diagnosis may thus be all the more considered as the risk of MCA-ID child is high.

What about spermatogenesis for these patients and the possible links between germ cell production and meiotic segregation? Abnormal semen parameters were found in $82.6 \%$ (19 for 23) of our RobT carriers which support the fact that semen parameters of RobT carriers are significantly lower than those of men with normal karyotype [53]. Altered semen parameters have previously been correlated with aneuploidy in RobT carriers [18] and suggested implication in malsegregation rates [21]. Here we confirm that normozoospermic men have higher rates of balanced spermatozoa than men with semen anomalies, whatever the anomaly implied. The proportion of RobT carriers with abnormal seminogram was not different among the translocations analyzed in our cohort (unpublished data) and particularly not between $\operatorname{der}(13 ; 14)$ and $\operatorname{der}(13 ; 15) \quad(p=0.58$, Fischer's exact test). The discrepancies between $\operatorname{der}(13 ; 15)$ and the other translocations cannot be explained this way.

It seems also interesting to question if the sperm preparation methods used in assisted reproductive techniques can improve the rates of balanced sperm used in these techniques. Several procedures have been developed to improve the detection or exclusion of sperm with quantitative or qualitative nuclear anomalies (translocation or DNA fragmentation) with partial results [54]. Among them, no morphological discrimination was sufficiently accurate to identify chromosomal imbalances or DNA defects [55, 56], but the use of a simple discontinuous gradient centrifugation could lead to a $30 \%$ decrease of unbalanced sperm in chromosomal structural rearrangement carriers [16]. Recent work by Rouen et al [57] suggests that the hypo-osmotic swelling test (HOST) could allow a more efficient selection of balanced sperm in translocation carriers. HOST has already shown some efficacy in normal sperm selection in patients with testicular biopsy and very low sperm count and/or little or no motility, but the efficiency of this procedure has yet to be confirmed under ICSI standard conditions.

Beyond basic cytogenetic research, these data are useful to bring better reproductive and genetic counseling when couples are engaged in PGD. Studies involving PGD for RobT carriers confirmed alternate segregation predominance [58-61]. We consider that sperm FISH is a useful tool to help the management of PGD attempts.

\section{Conclusion}

According to the discrepancies observed between der $(13 ; 15)$ and all the other Rob $\mathrm{T}$ carriers, the differences observed among patients presenting normal and abnormal sperm parameters and the input in genetical counselling, sperm FISH does not seem obsolete for these patients. Moreover, it seems important to collect more data for rare RobT. 


\section{Abbreviations}

FISH: Fluorescence In-Situ Hybridization; HOST: Hypo-Osmotic Swelling Test: MCA-ID: Multiple Congenital Anomalies and Intellectual Disability; OAT: OligoAsthenoTeratozoospermia; PGD: Preimplantation Genetic Diagnosis; RobT: Robertsonian translocation; SSC: Saline-Sodium-Citrate buffer; WHO: World Health Organization

\section{Acknowledgements}

Not applicable

\section{Funding}

This work started with a grant from the Délégation de la Recherche Clinique CHU Grenoble, 2004

\section{Availability of data and materials}

All data generated or analysed during this study are included in this published article (and its supplementary information files).

\section{Authors' contributions}

AL, GM, FD and SH analyzed the data and wrote the manuscript. AL, GM and FD performed sperm FISH experiments. AL, GM and JPH performed the literature analysis and statistical analysis. VS, CC, FA, RH, JB, JL, MB and SB included patients and/or provided clinical samples and data. SH designed the study, had full access to all of the data in the study and takes responsibility for the integrity of the data and its accuracy. All authors contributed to the report. All authors read and approved the final manuscript.

\section{Ethics approval and consent to participate}

All patients signed inform consent and study was approved by the ethic committee of the University Hospital of Grenoble.

\section{Consent for publication}

Not applicable

\section{Competing interests}

The authors declare that they have no competing interests.

\section{Publisher's Note}

Springer Nature remains neutral with regard to jurisdictional claims in published maps and institutional affiliations.

\section{Author details}

${ }^{1} \mathrm{CHU}$ de Grenoble, UF de Biologie de la procréation, F-38000 Grenoble, France. ${ }^{2} \mathrm{CHU}$ de Grenoble, UF de Génétique Chromosomique, F-38000 Grenoble, France. ${ }^{3}$ Université Grenoble Alpes, F-38000 Grenoble, France. 4Team 'Genetics Epigenetics and Therapies of Infertility', Institute for Advanced Biosciences INSERM U1209, CNRS UMR5309, F-38000 Grenoble, France. ${ }^{5}$ Service de génétique CH de Chambéry, Chambery F-38000, France. ${ }^{6}$ Centre d'AMP, HFME, CHU de Lyon, Lyon F-69000, France.

\section{Received: 6 December 2017 Accepted: 8 March 2018}

\section{Published online: 07 May 2018}

\section{References}

1. Nielsen J, Wohlert M. Chromosome abnormalities found among 34,910 newborn children: results from a 13-year incidence study in Arhus, Denmark. Hum Genet. 1991:87:81-3.

2. Therman E, Susman B, Denniston C. The nonrandom participation of human acrocentric chromosomes in Robertsonian translocations. Ann Hum Genet. 1989:53:49-65.

3. Fryns JP, van Buggenhout G. Structural chromosome rearrangements in couples with recurrent fetal wastage. Eur J Obstet Gynecol Reprod Biol. 1998;81:171-6.

4. Escudero T, Abdelhadi I, Sandalinas M, Munne S. Predictive value of sperm fluorescence in situ hybridization analysis on the outcome of preimplantation genetic diagnosis for translocations. Fertil Steril. 2003; 79(Suppl3):1528-34.

5. Mau-Holzmann UA. Somatic chromosomal abnormalities in infertile men and women. Cytogenet Genome Res. 2005;111:317-36.
6. World Health Organization. WHO Laboratory manual for the examination of human semen and sperm-cervical mucus interaction. 4th ed. Cambridge: Cambridge University Press; 1999

7. Molina O, Sarrate Z, Vidal F, Blanco J. FISH on sperm: spot-counting to stop counting? Not yet. Fertil Steril. 2009;92:1474-80.

8. Martinez G, Le Mitouard M, Borye R, Esquerré C, Satre V, Bujan L, et al. FISH and tips: a large scale analysis of automated versus manual scoring for sperm aneuploidy detection. Basic And Clinical Andrology. 2013;23:13.

9. Wang B, Nie B, Tang D, Li R, Liu X, Song J, et al. Analysis of meiotic segregation patterns and interchromosomal effects in sperm from 13 robertsonian translocations. BJMG. 2017;20:43-50.

10. Song J, Li X, Sun L, Xu S, Liu N, Yao Y, et al. A family with Robertsonian translocation: a potential mechanism of speciation in humans. Mol Cytogenet. 2016;9(48)

11. Godo A, Blanco J, Vidal F, Sandalinas M, Garcia-Guixe E, Anton E. Altered segregation pattern and numerical chromosome abnormalities interrelate in spermatozoa from Robertsonian translocation carriers. Reprod BioMed Online. 2015;31:79-88

12. Sobotka V, Vozdova M, Heracek J, Rubes J. A rare Robertsonian translocation rob(14;22) carrier with azoospermia, meiotic defects, and testicular sperm aneuploidy. Syst Biol Reprod Med. 2015;61:245-50.

13. Xu S, Tang D, Fang K, Xia Y, Song J, Wang W, et al. Analysis of meiotic segregation patterns and interchromosomal effects in sperm from a Robertsonian translocation family. Biomed Res. 2014;25:233-9.

14. Perrin A, Nguyen MH, Bujan L, Vialard F, Amice V, Gueganic N, et al. DNA fragmentation is higher in spermatozoa with chromosomally unbalanced content in men with a structural chromosomal rearrangement. Andrology. 2013;1:632-8.

15. Pylyp LY, Zukin VD, Bilko NM. Chromosomal segregation in sperm of Robertsonian translocation carriers. J Assist Reprod Genet. 2013;30:1141-5.

16. Rouen A, Balet R, Dorna M, Hyon C, Pollet-Villard X, Chantot-Bastaraud S, et al. Discontinuous gradient centrifugation (DGC) decreases the proportion of chromosomally unbalanced spermatozoa in chromosomal rearrangement carriers. Hum Reprod. 2013;28:2003-9.

17. Rouen A, Pyram K, Pollet-Villard X, Hyon C, Dorna M, Marques S, et al. Simultaneous cell by cell study of both DNA fragmentation and chromosomal segregation in spermatozoa from chromosomal rearrangement carriers. J Assist Reprod Genet. 2013;30:383-90.

18. Vozdova M, Oracova E, Kasikova K, Prinosilova P, Rybar R, Horinova V, et al. Balanced chromosomal translocations in men: relationships among semen parameters, chromatin integrity, sperm meiotic segregation and aneuploidy. J Assist Reprod Genet. 2013;30:391-405.

19. Bernicot I, Schneider A, Mace A, Hamamah S, Hedon B, Pellestor F, et al. Analysis using fish of sperm and embryos from two carriers of rare rob(13, 21) and rob(15;22) robertsonian translocation undergoing PGD. Eur J Med Genet. 2012;55:245-51.

20. Cassuto NG, Le Foll N, Chantot-Bastaraud S, Balet R, Bouret D, Rouen A, et al. Sperm fluorescence in situ hybridization study in nine men carrying a Robertsonian or a reciprocal translocation: relationship between segregation modes and high-magnification sperm morphology examination. Fertil Steril. 2011;96:826-32.

21. Ferfouri F, Selva J, Boitrelle F, Gomes DM, Torre A, Albert M, et al. The chromosomal risk in sperm from heterozygous Robertsonian translocation carriers is related to the sperm count and the translocation type. Fertil Steril. 2011:96:1337-43.

22. Mahjoub M, Mehdi M, Brahem S, Elghezal H, Ibala S, Saad A. Chromosomal segregation in spermatozoa of five Robertsonian translocation carriers t(13; 14). J Assist Reprod Genet. 2011;28:607-13.

23. Anton E, Blanco J, Vidal F. Meiotic behavior of three D;G Robertsonian translocations: segregation and interchromosomal effect. J Hum Genet. 2010;55:541-5.

24. Brugnon F, Janny L, Communal Y, Darcha C, Szczepaniak C, Pellestor F, et al. Apoptosis and meiotic segregation in ejaculated sperm from Robertsonian translocation carrier patients. Hum Reprod. 2010;25:1631-42.

25. Perrin A, Morel F, Douet-Guilbert N, Le Bris MJ, Amice J, Amice V, et al. A study of meiotic segregation of chromosomes in spermatozoa of translocation carriers using fluorescent in situ hybridisation. Andrologia. 2010:42:27-34.

26. Perrin A, Caer E, Oliver-Bonet M, Navarro J, Benet J, Amice V, et al. DNA fragmentation and meiotic segregation in sperm of carriers of a chromosomal structural abnormality. Fertil Steril. 2009;92(2) 
27. Nishikawa N, Sato T, Suzumori N, Sonta S, Suzumori K. Meiotic segregation analysis in male translocation carriers by using fluorescent in situ hybridization. Int J Androl. 2008;31:60-6.

28. Chen Y, Huang J, Liu P, Qiao J. Analysis of meiotic segregation patterns and interchromosomal effects in sperm from six males with Robertsonian translocations. J Assist Reprod Genet. 2007;24:406-11.

29. Kekesi A, Erdei E, Torok M, Dravucz S, Toth A. Segregation of chromosomes in spermatozoa of four Hungarian translocation carriers. Fertil Steril. 2007;88: 212.e5-11.

30. Brugnon F, Van Assche E, Verheyen G, Sion B, Boucher D, Pouly JL, et al. Study of two markers of apoptosis and meiotic segregation in ejaculated sperm of chromosomal translocation carrier patients. Hum Reprod. 2006;21: 685-93.

31. Hatakeyama C, Gao H, Harmer K, Ma S. Meiotic segregation patterns and ICSI pregnancy outcome of a rare $(13 ; 21)$ Robertsonian translocation carrier: a case report. Hum Reprod. 2006;21:976-9.

32. Moradkhani K, Puechberty J, Bhatt S, Lespinasse J, Vago P, Lefort G, et al. Rare Robertsonian translocations and meiotic behaviour: sperm FISH analysis of t(13;15) and t(14;15) translocations: a case report. Hum Reprod. 2006;21:3193-8

33. Moradkhani K, Puechberty J, Bhatt S, Vago P, Janny L, Lefort G, et al. Meiotic segregation of rare Robertsonian translocations: sperm analysis of three t(14q;22q) cases. Hum Reprod. 2006;21:1166-71.

34. Ogur G, Van Assche E, Vegetti W, Verheyen G, Tournaye H, Bonduelle M, et al. Chromosomal segregation in spermatozoa of 14 Robertsonian translocation carriers. Mol Hum Reprod. 2006;12:209-15.

35. Tang YP, Liu XS, Liu Y, Yang ZR, Chen Y, Xiong CL. Somatic cell and sperm cell cytogenetics in a patient with $\mathrm{t}(14 ; 21)$. Yi Chuan Xue Bao. 2006;33:488-94.

36. Anahory T, Hamamah S, Andreo B, Hedon B, Claustres M, Sarda P, et al. Sperm segregation analysis of a $(13 ; 22)$ Robertsonian translocation carrier by FISH: a comparison of locus-specific probe and whole chromosome painting. Hum Reprod. 2005;20:1850-4.

37. Rives N, Ravel C, Duchesne V, Siffroi JP, Mousset-Simeon N, Mace B. Molecular cytogenetics analysis with whole chromosome paint probes of sperm nuclei from a $(13 ; 15)$ Robertsonian translocation carrier. J Hum Genet. 2005:50:360-4.

38. Roux C, Tripogney C, Morel F, Joanne C, Fellmann F, Clavequin MC, Bresson $J$. Segregation of chromosomes in sperm of Robertsonian translocation carriers. Cytogenet Genome Res. 2005;111:291-6.

39. Anton E, Blanco J, Egozcue J, Vidal F. Sperm FISH studies in seven male carriers of Robertsonian translocation t(13;14)(q10;q10). Hum Reprod. 2004; 19:1345-51.

40. Frydman N, Romana S, Le Lorc'h M, Vekemans M, Frydman R, Tachdjian G. Assisting reproduction of infertile men carrying a Robertsonian translocation. Hum Reprod. 2001;16:2274-7.

41. Morel F, Fellmann F, Roux C, Bresson JL. Meiotic segregation analysis by FISH investigation of spermatozoa of a $46, Y, \operatorname{der}(X), t(X ; Y)(q t e r->p 22:: q 11-$ >qter) carrier. Cytogenet Cell Genet. 2001;92:63-8.

42. Escudero T, Lee M, Carrel D, Blanco J, Munne S. Analysis of chromosome abnormalities in sperm and embryos from two 45,XY,t(13;14)(q10;q10) carriers. Prenat Diagn. 2000;20:599-602.

43. Honda H, Miharu N, Samura O, He H, Ohama K. Meiotic segregation analysis of a 14;21 Robertsonian translocation carrier by fluorescence in situ hybridization. Hum Genet. 2000;106:188-93.

44. Ogawa S, Araki S, Araki Y, Ohno M, Sato I. Chromosome analysis of human spermatozoa from an oligoasthenozoospermic carrier for a 13;14 Robertsonian translocation by their injection into mouse oocytes. Hum Reprod. 2000;15:1136-9.

45. Mennicke K, Diercks P, Schlieker H, Bals-Pratsch M, Al Hasani S, Diedrich K, Schwinger E. Molecular cytogenetic diagnostics in sperm. Int J Androl. 1997; 20:11-9.

46. Rousseaux S, Chevret E, Monteil M, Cozzi J, Pelletier R, Delafontaine D, Sele B. Sperm nuclei analysis of a Robertsonian t(14q21q) carrier, by FISH, using three plasmids and two YAC probes. Hum Genet. 1995;96:655-60.

47. Martin RH, Ko E, Hildebrand K. Analysis of sperm chromosome complements from a man heterozygous for a robertsonian translocation 45,XY,t(15q;22q). Am J Med Genet. 1992;43:855-7.

48. Syme RM, Martin RH. Meiotic segregation of a 21;22 Robertsonian translocation. Hum Reprod. 1992;7:825-9.
49. Pellestor $F$. Analysis of meiotic segregation in a man heterozygous for a 13; 15 Robertsonian translocation and a review of the literature. Hum Genet. 1990;85:49-54

50. Martin $\mathrm{RH}$. Cytogenetic analysis of sperm from a male heterozygous for a 13;14 Robertsonian translocation. Hum Genet. 1988a;80:357-61.

51. Pellestor F, Sele B, Jalbert H. Chromosome analysis of spermatozoa from a male heterozygous for a 13;14 Robertsonian translocation. Hum Genet. 1987;76:116-20.

52. Balkan W, Martin RH. Segregation of chromosomes into the spematozoa of a man heterozygous for a 14;21 Robertsonian translocation. Am J Med Genet. 1983b:16:169-72.

53. Pastuszek E, Kiewisz J, Kulwikowska PM, Lukaszuk M, Lukaszuk K. Sperm parameters and DNA fragmentation of balanced chromosomal rearrangements carriers. Folia Histochem Cytobiol. 2015;53:314-21.

54. Sakkas D. Novel technologies for selecting the best sperm for in vitro fertilization and intracytoplasmic sperm injection. Fertil Steril. 2013;99:1023-9.

55. Garolla A, Fortini D, Menegazzo M, de Toni L, Nicoletti V, Moretti A, et al. High-power microscopy for selecting spermatozoa for ICSI by physiological status. Reprod BioMed Online. 2008;17:610-6.

56. Avendano C, Franchi A, Taylor S, Morshedi M, Bocca S, Oehninger S. Fragmentation of DNA in morphologically normal human spermatozoa. Fertil Steril. 2009:91:1077-84

57. Rouen A, Carlier L, Heide S, Egloff M, Marzin P, Ader F, et al. Potential selection of genetically balanced spermatozoa based on the hypo-osmotic swelling test in chromosomal rearrangement carriers. Reprod BioMed Online. 2017:35:372-8

58. Conn CM, Harper JC, Winston RM, Delhanty JD. Infertile couples with Robertsonian translocations: preimplantation genetic analysis of embryos reveals chaotic cleavage divisions. Hum Genet. 1998;102:117-23.

59. Iwarsson E, Malmgren H, Inzunza J, Ahrlund-Richter L, Sjöblom P, Rosenlund $B$, et al. Highly abnormal cleavage divisions in preimplantation embryos from translocation carriers. Prenat Diagn. 2000;20:1038-47.

60. Scriven PN, Flinter FA, Braude PR, Ogilvie CM. Robertsonian translocationsreproductive risks and indications for preimplantation genetic diagnosis. Hum Reprod. 2001:16:2267-73.

61. Alves C, Sousa M, Silva J, Barros A. Preimplantation genetic diagnosis using FISH for carriers of Robertsonian translocations: the Portuguese experience. Prenat Diagn. 2002;22:1153-62.

\section{Submit your next manuscript to BioMed Central and we will help you at every step:}

- We accept pre-submission inquiries

- Our selector tool helps you to find the most relevant journal

- We provide round the clock customer support

- Convenient online submission

- Thorough peer review

- Inclusion in PubMed and all major indexing services

- Maximum visibility for your research

Submit your manuscript at www.biomedcentral.com/submit 